\title{
OBSTRUÇÃO BAIXA DE CANAIS LACRIMAIS: UM RELATO DE CASO
}

\section{LOW CONSTRUCTION OF LACRIMAL CHANNELS: A CASE REPORT}

Cláudia Regina Dias Cestari ${ }^{1}$, Eduarda Belasque Vriesmann ${ }^{1 *}$, Beatriz Maistro ${ }^{1}$, Caroline Maistro ${ }^{1}$, Izzabelle Karolinne Sthephanne Bogdan².

1 UNINGÁ - Centro Universitário Ingá, Maringá, PR, Brasil.

${ }^{2}$ Hospital Metropolitano de Sarandi, Maringá, PR, Brasil.

*dudabelasque@hotmail.com

\section{RESUMO}

As lágrimas produzidas pelas glândulas lacrimais têm como função a lubrificação adequada dos olhos. Quando há alguma obstrução neste caminho, ocorre a presença de lacrimejamento exacerbado e irritação na órbita acometida, podendo evoluir com complicações como a dacrioestenose baixa. Esta patologia é comumente encontrada em neonatos e crianças nos primeiros anos de vida, evoluindo com resolução espontânea. De forma rara, essa condição pode ser encontrada em jovens que apresentam infecções crônicas das vias de drenagem lacrimal. Neste relato, tem-se como objetivo discutir um caso de obstrução baixa de canais lacrimais, ocasionada por sinusites de repetição, e que necessitou de uma dacriocistorinostomia. Paciente, B.M., sexo feminino, 23 anos que procurou serviço oftalmológico devido a queixa de lacrimejamento ocular bilateral, associado a dacriocistites de repetição e hiperemia na região do saco lacrimal. Foi indicado conduta expectante associada a massagens periocular para facilitar a drenagem da lágrima. Após 1 ano, sem melhora, foi referenciada à equipe da cirurgia otorrinolaringológica pela intensificação da queixa. A equipe responsável solicitou a realização de uma dacriocistografia bilateral que mostrou, após cateterização e injeção de contraste radiopaco: não opacificação de ambos os ductos lacrimo-nasais, caracterizando obstrução a este nível. Com o resultado do exame, foi indicado a dacriocistorinostomia endoscópica, a qual a paciente foi submetida. Este procedimento consiste basicamente na abertura do saco lacrimal, que é conectado ao nariz, pela remoção do osso e da mucosa entre essas duas estruturas, ao nível do meato médio. Um retalho de mucosa nasal é criado no primeiro momento, seguido da osteotomia endonasal para expor 0 saco lacrimal e a marsupialização do mesmo para o interior da cavidade nasal. Após o procedimento, realizou-se a passagem da sonda de Crawford, através dos canalículos superior e inferior dos olhos, a qual foi fixada internamente no nariz e deverá permanecer por no mínimo 4 semanas. Conclui-se, dessa forma, que a dacriocistorinostomia endoscópica possui alta taxa de sucesso no alívio do lacrimejamento ocular, quando bem indicada. Além disso, outras afecções nasossinusais podem ser corrigidas durante o procedimento, como no caso relatado, em que foi realizado juntamente correção de desvio septo e a hipertrofia das conchas nasais.

Palavras-chave: Dacriocistite. Dacriocistorinostomia. Ducto nasolacrimal. Osteotomia. Sinusite etmoidal. 